\title{
HARMFUL ALGAL BLOOMS MONITORING USING SENTINEL-2 SATELLITE IMAGES
}

\author{
M. H. Khalili ${ }^{1}$, M. Hasanlou ${ }^{2 *}$ \\ ${ }^{1}$ Dept. of Geomatic and Geospatial Engineering, Universityof Tehran, Kargar Street, Tehran, m.hossein.khalili@ut.ac.ir \\ ${ }^{2}$ Dept. of Geomatic and Geospatial Engineering, Universityof Tehran, Kargar Street, Tehran, hasanlou@ut.ac.ir
}

KEYWORDS: Red tide, Harmful Algal Blooms (HAB), Sentinel-2, Lantau Island, Hongkong, Spectral feature

\begin{abstract}
:
Over the last few decades in coastal areas, the occurrence of Harmful Algal Blooms (HAB) has increased. The phenomenon is harmful to the health of coastal residents as well as marine organisms and can cause damage to the economy of the region. In this article, considering the need of a method for detecting red tide phenomenon using high spatial resolution satellite images, we tried to test the capability of spectral features, which can be generated using Sentinel-2 satellite images, in detecting red tide phenomenon. For this purpose, we generated an algorithm for detecting spectral features, which the red tide phenomenon causes a noticeable change in their value compared with the non-blooming condition. The ability of the selected spectral features in detecting HABs has been evaluated using statistical methods such as type I and II error, overall accuracy, kappa coefficient, and ROC curves. The best case, for the spectral feature, is $\left(R_{4}-R_{8 A}\right) /\left(R_{4}+R_{8 A}\right), 5 \%$ for type I and $6 \%$ for type II error were achieved where $R_{4}$ stands for reflectance in band 4 and $R_{8 A}$ is the reflectance in band $8 \mathrm{~A}$ of a Sentinel-2 satellite image.
\end{abstract}

\section{INTRODUCTION}

According to (Ricardson, 1997), the definition of an algal bloom is "the rapid growth of one or more species which leads to an increase in biomass of the species". If the rapid growth is related to a harmful or toxic species, then it is called Harmful Algal Bloom (HAB). A species can be harmful due to the release of toxic substances, which can harm human health as well as marine organisms, or deplete dissolved oxygen in the water and causing mortality of marine organisms (Tang et al, 2006). Development, stability, and density of the phenomenon are related to some environmental factors such as wind velocity, Sea Surface Temperature (SST), currents, and nutrient concentration. (Tang et al, 2006) reviewed this connection using SeaWiFS ocean color data, AVHRR SST data, and satellite altimeter information. According to their study, HABs generally need adequate nutrient concentrations, enough sunlight and warm water temperatures can be transported by local circulations and winds.

There are different ways to detect and monitor HABs such as applying anomaly detecting algorithms to satellite images and products or visual analysis of ocean color data. (Miller, 2006) applied multivariable classification and an anomaly detecting algorithm to SeaWiFS ocean color data to detect HABs. (Kurekin et al, 2014) used an almost similar way to detect the red tide phenomenon occurred in west waters of Netherlands. He used field data along with visual analysis of MODIS ocean color data to classify different types of the area in bloom, no-bloom or harmful bloom categories. Other similar studies include (Shutler et al, 2012), (Banks et al, 2012) and (Anderson et al, 2011). It can be noticed that these researches are based on anomaly detecting, difference detecting and visual analysis methods that only can detect those pixels, which have a different spectral response compared with the background and give no information about the nature of the pixel.

Generating an index is another way to detect HABs. (Ahn, Shangumam, 2006) generated an index to detect HABs in optically complex Northeast-Asia coastal waters. The index is presented in equation (1).

$$
R I=\frac{L_{w}(510) / L_{w}(555)-L_{w}(443)}{L_{w}(510) / L_{w}(555)+L_{w}(443)}
$$

where $\mathrm{L}_{\mathrm{w}}(\lambda)$ is the reflectance which is corrected for the skylight reflection and the air-sea interface effects. According to (Siswanto et al, 2013), the need for additional complicated corrections can reduce the applicability of this method.

Spectral band ratio algorithms can be used to detect different types of algal blooms. In coastal waters, empirical visible-NIR band ratios are common types of band combinations which have been used by researchers to monitor HABs (Gitelson et al, 2009). (Carvalho, 2011) used empirical blue-green band ratio along with anomaly detecting methods to identify HABs along the west coast of Florida. (Ahn et al, 2006) and (Kahru et al, 2004) are some other researches that rely on spectral band ratio methods.

There are also various forms of spectral band difference algorithms which use the visible and NIR portion of the spectrum and have been used by researchers such as (Shanmugam, 2008), (Zhao et al, 2010) and (Matthews et al, 2012) to detect different types of algal blooms.

Except for a few research that used high spatial-poor temporal resolution Landsat satellite images only for visual analysis (such as (Yunus, Dou, et al, 2015), most of the HAB detecting and monitoring methods are designed for SeaWiFS, MODIS and MERIS. These sensors despite having a high temporal resolution (about one day), have a poor spatial resolution (250 1130 meters). Although, this category of sensors, allows us to continuously monitor the behavior of the phenomenon, limits us to a detailed examination of HABs and only large scale HABs can be monitored by using them (Blondeau, 2014). Therefore, an examination of a high spatial and temporal sensor's capability to detect and monitor HABs sounds essential. 
Sentinel-2 high spatial-temporal satellite images (5 6 days for temporal and 10,20 and 60 meters for spatial resolution) have made it possible to detect and monitor HABs more accurately at small areas. In this research, we have examined the ability of some spectral features, generated using band 2, 3, 4, 8 and $8 \mathrm{~A}$ of Sentinel-2 satellite images, in detecting of HABs using statistical methods. The case study is east waters of Lantau Island, Hongkong. For this purpose, we used three Sentinel-2 satellite images which one of them is taken in the presence of the HAB and the other two are taken in non-blooming condition. By comparing the numerical value of the spectral indices in blooming and non-blooming condition, indices, which the phenomenon causes a noticeable change in their value, have been extracted. Finally, by classifying the study area using any of the spectral indices and calculating the statistical parameters, determining the accuracy and quality of the classification, the capability of spectral indices in HAB detecting has been discussed.

\section{DATA AND METHOD}

\subsection{Case study}

Lantau Island is the largest island in Hongkong (Figure 1.) According to the Hongkong red tide database (https://www.afcd.gov.hk) reports, the largest HAB of the last three years in Hongkong has occurred in the eastern waters of Lantau island. The phenomenon had covered an area about 130 million square kilometers between longitude 114.0205 to 114.1155 degrees and latitude 22.17995 to 22.3467 degrees. The species causing the phenomenon was Thalassiosira Pseudonana with a concentration over than $50000 \mathrm{cell} / \mathrm{ml}$.

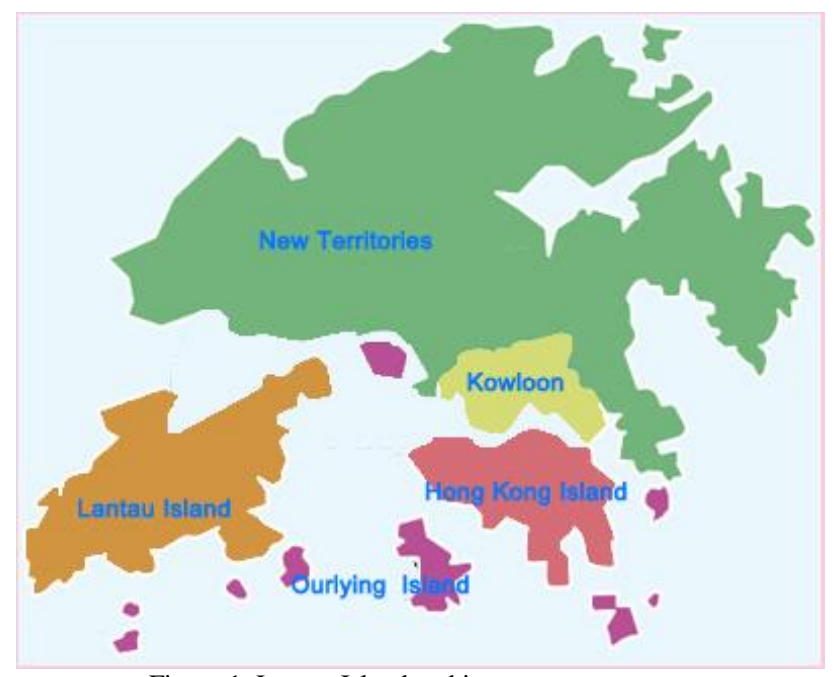

Figure 1. Lantau Island and its eastern waters

\subsection{Satellite images and atmospheric correction}

For the purpose of testing Sentinel-2 satellite image's ability to monitor HABs, we used three images which one of them is taken in the presence of the phenomenon and the other two is taken in non-blooming condition. Due to the higher capability of the bands located in visible and NIR portion of the spectrum in HAB detecting (Blondeau, 2014), we used band 2, 3, 4, 8 and 8A of Sentinel-2 satellite images to generate spectral features. Table 1 presents the spectral properties of these five bands.

Atmospheric corrections applied to all three images, using SNAP's sen2cor toolbox. In addition, sen2cor image classification output is used to separate cloudy pixels from noncloudy ones.
Table 1. Spectral properties of Sentinel-2 band 2, 3, 4, 8 and $8 \mathrm{~A}$

\begin{tabular}{cccc}
\hline $\begin{array}{c}\text { Band } \\
\text { number }\end{array}$ & $\begin{array}{c}\text { Central wavelength } \\
(\mu \mathrm{m})\end{array}$ & $\begin{array}{c}\text { Spatial } \\
\text { resolution } \\
(\text { meter })\end{array}$ & $\begin{array}{c}\text { Bandwidth } \\
(\mathrm{nm})\end{array}$ \\
\hline 2 & 0.490 & 10 & 95 \\
3 & 0.560 & 10 & 47 \\
4 & 0.665 & 10 & 39 \\
8 & 0.842 & 10 & 115 \\
$8 \mathrm{~A}$ & 0.865 & 20 & 20 \\
\hline
\end{tabular}

\subsection{Methods}

When comparing the reflectance of the corresponding pixels in images, it was found that this comparison for a large number of pixels couldn't be performed due to the cloudiness of at least one of the three pixels. To solve this problem, we gridded the study area (Figure 2) and instead of comparing spectral response on the corresponding pixels, the average reflectance on the corresponding patches has been compared.

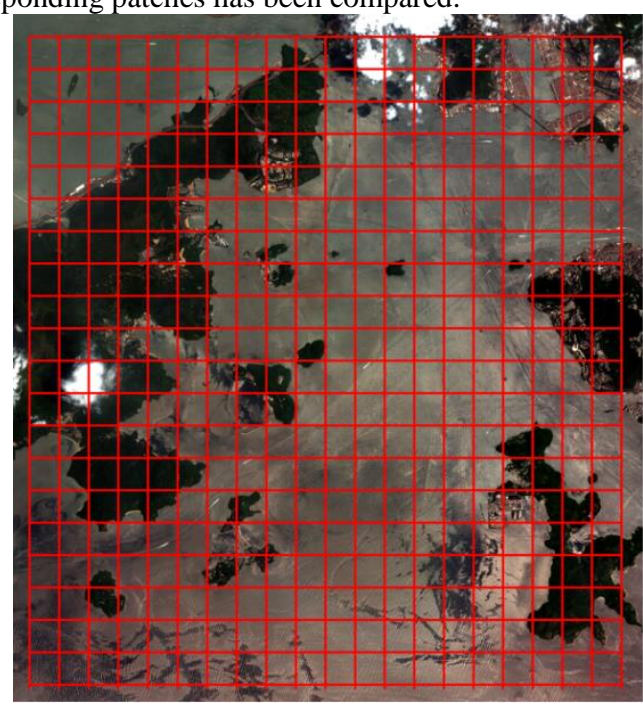

Figure 2. Networking the study area

Following the networking of the study area, all patches that contain an insufficient number of non-cloudy pixels was ignored in the rest of our calculations. Then spectral indices which have been presented in equation 2, 3 and 4 was calculated for all of the remaining patches.

$$
\begin{gathered}
r(i, j)=\frac{R(i)}{R(j)} \quad i=2,3,4,8,8 A \text { and } i \neq j \\
d(i, j)=R(i)-R(j) \quad i=2,3,4,8,8 A \text { and } i \neq j \\
n(i, j)=\frac{R(i)-R(j)}{R(i)+R(j)} \quad i=2,3,4,8,8 A \text { and } i \neq j
\end{gathered}
$$

where $R(i)$ stands for the reflectance recorded in band number $i$ of a Sentinel-2 satellite image. In the next step, by applying some filters, patches that may not be appropriate for extracting spectral indices to detect red tide phenomenon are eliminated. These filters are:

- $\quad$ Removing patches, which the red tide phenomena have had a slight or no effect on their spectral response graphs due to lack of occurrence or low concentration. Removing patches, which the difference in their spectral response during the occurrence of the phenomenon in comparison with the non-blooming 
condition, is not related to the red tide such as cloudy patches.

- Removing patches which their spectral response during the occurrence of the phenomenon is unusually different from the normal condition.

Finally, after determining the effective patches, by numerical comparison of their spectral indices during the occurrence of the red tide phenomenon and non-blooming condition, spectral indices, which are probably effective in, HAB detecting can be identified. The ability of the selected spectral features in HAB detecting has been evaluated using statistical methods such as type I and II error, overall accuracy, kappa coefficient, and ROC curves.

\section{RESULTS}

The methods were applied to three Sentinel-2/MSI satellite images that were taken from the study area on July 14, 2017 (before the occurrence of the phenomenon), July 28, 2017 (during the occurrence of the phenomenon) and August 8, 2017 (after the occurrence of the phenomenon).

The study area has been gridded and all patches have been investigated in order to find the effective patches which can be used to extract spectral features that probably have the ability to detect HABs. Two patches out of 400 have been selected which their position in the study area is shown in Figure 3.

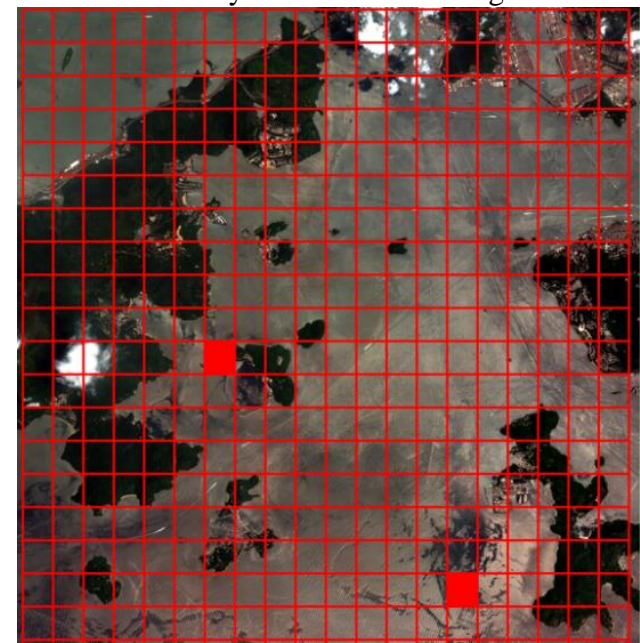

Figure 3. Selected patches in order to identify effective spectral features to detect HABs

The graph of the spectral response related to these two patches is shown in Figure 4.

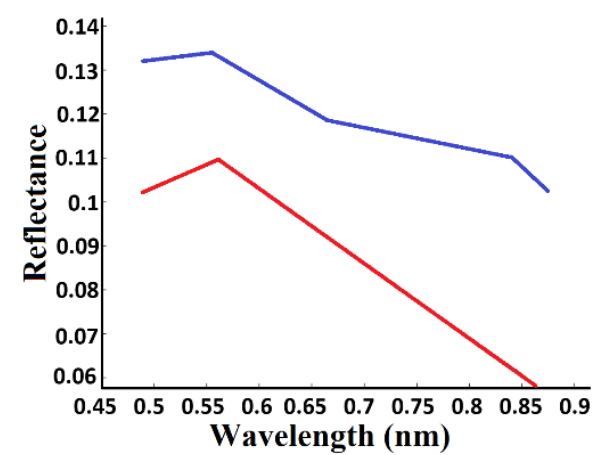

Figure 4. The Spectral response of the two selected patches. The red graph represents the spectral response during the occurrence of $\mathrm{HAB}$

while the blue one shows the spectral response in non-blooming condition

The difference in the spectral response of these patches during the presence of the phenomenon comparing with the normal condition can be seen in the generated spectral indices graph (Figure 5).

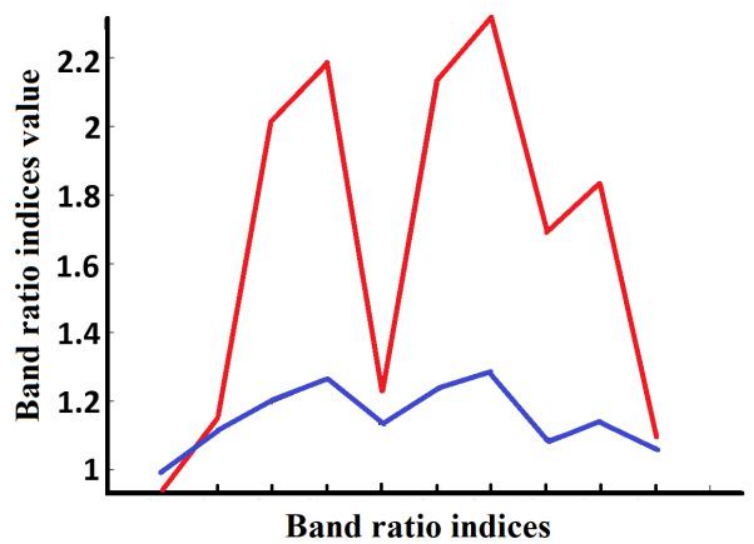

(a)

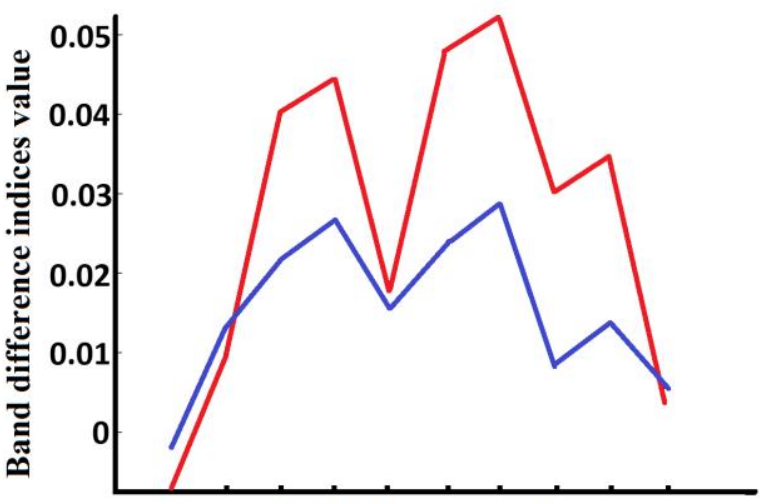

Band difference indices

(b)

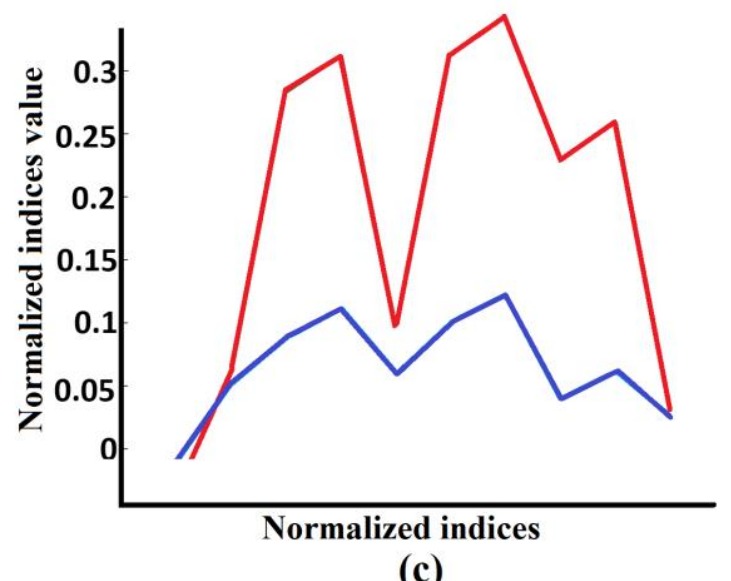

Figure 5. Spectral band ratio (a), difference (b) and normalized (c) indices generated using the average reflectance of two selected patches. The red graph is related to blooming condition and the blue one is related to the non-blooming condition

Using numerical comparison, spectral features which the red tide phenomenon causes a noticeable change in their value have been extracted. The ideal thresholds of the extracted indices have been determined using ROC curves. Table 2, represents the extracted indices and their corresponding ideal threshold. 
Table 2. Extracted indices and their corresponding ideal thresholds

\begin{tabular}{cc}
\hline Indices & Threshold \\
\hline $\mathrm{R}(2) / \mathrm{R}(8)$ & 1.5575 \\
$\mathrm{R}(2) / \mathrm{R}(8 \mathrm{~A})$ & 1.5107 \\
$\mathrm{R}(3) / \mathrm{R}(8)$ & 1.7063 \\
$\mathrm{R}(3) / \mathrm{R}(8 \mathrm{~A})$ & 1.6043 \\
$\mathrm{R}(4) / \mathrm{R}(8)$ & 1.3984 \\
$\mathrm{R}(4) / \mathrm{R}(8 \mathrm{~A})$ & 1.3224 \\
$\mathrm{R}(2)-\mathrm{R}(8)$ & 0.0402 \\
$\mathrm{R}(4)-\mathrm{R}(8)$ & 0.0284 \\
$\mathrm{R}(4)-\mathrm{R}(8 \mathrm{~A})$ & 0.0241 \\
{$[\mathrm{R}(2)-\mathrm{R}(8)] /[\mathrm{R}(2)+\mathrm{R}(8)]$} & 0.1976 \\
{$[\mathrm{R}(2)-\mathrm{R}(8 \mathrm{~A})] /[\mathrm{R}(2)+\mathrm{R}(8 \mathrm{~A})]$} & 0.1852 \\
{$[\mathrm{R}(3)-\mathrm{R}(8)] /[\mathrm{R}(3)+\mathrm{R}(8)]$} & 0.2103 \\
{$[\mathrm{R}(3)-\mathrm{R}(8 \mathrm{~A})] /[\mathrm{R}(3)+\mathrm{R}(8 \mathrm{~A})]$} & 0.2218 \\
{$[\mathrm{R}(4)-\mathrm{R}(8)] /[\mathrm{R}(4)+\mathrm{R}(8)]$} & 0.1380 \\
{$[\mathrm{R}(4)-\mathrm{R}(8 \mathrm{~A})] /[\mathrm{R}(4)+\mathrm{R}(8 \mathrm{~A})]$} & 0.1301 \\
\hline
\end{tabular}

Figure 6 , shows the areas identified by spectral feature $[\mathrm{R}(4)-\mathrm{R}(8 \mathrm{~A})] /[\mathrm{R}(4)+\mathrm{R}(8 \mathrm{~A})]$ as $\mathrm{HAB}$.

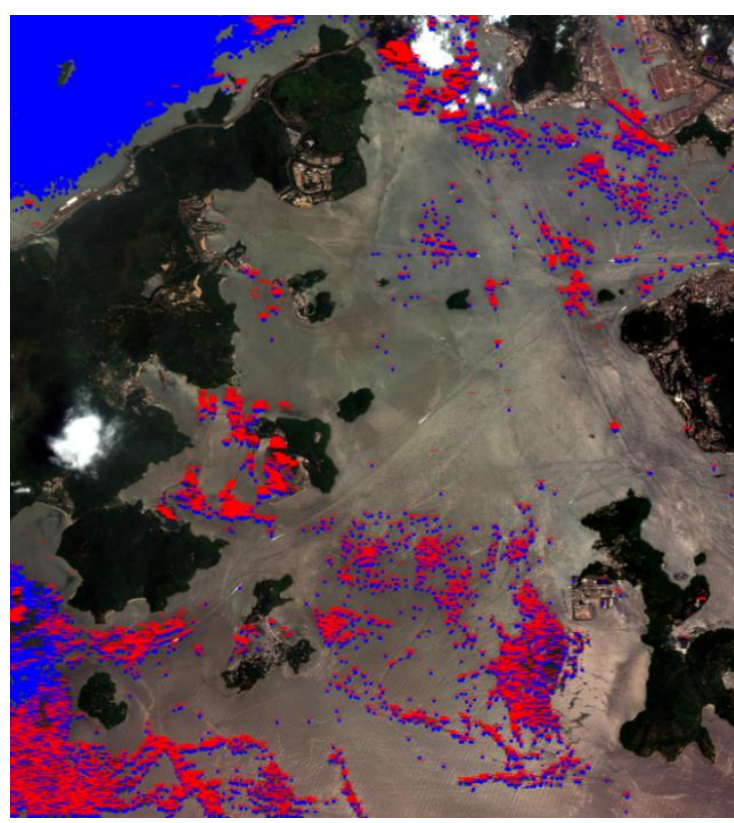

Figure 6. Red areas represent $\mathrm{HAB}$

The ROC curves for three spectral features is shown in Figure 7. These curves are plotted after classifying the study area using a range of thresholds and calculation of each classification's type I and II error.

\section{DISCUSSION}

Different statistical parameters such as type I and II error, overall accuracy (ACC), Kappa coefficient and AUC (the area under the ROC curve) were calculated for each spectral index in order to evaluate the efficiency of each index in detecting HABs. To calculate these parameters, the classification results using indices were compared with Hong Kong red tide database reports. The Hong Kong red tide database provides information about HABs, which have occurred in Hong Kong such as start and end date, type, and concentration of the species that generates the phenomenon and approximate area covered by the phenomenon. Table 3 shows the statistical parameters calculated for each spectral index.
Table 3. Statistical parameters calculated for each index in order to evaluate their ability in HAB detecting

\begin{tabular}{cccccc}
\hline Index & $\begin{array}{c}\text { Type I } \\
\text { error } \\
(\%)\end{array}$ & $\begin{array}{c}\text { Type } \\
\text { II error } \\
(\%)\end{array}$ & $\begin{array}{c}\text { Overall } \\
\text { accuracy } \\
(\%)\end{array}$ & Kappa & AUC \\
\hline $\mathrm{r}(2,8)$ & 19 & 18.5 & 81.43 & 0.3233 & 0.86 \\
$\mathrm{r}(2,8 \mathrm{~A})$ & 3.5 & 6.4 & 93.82 & 0.6744 & 0.98 \\
$\mathrm{r}(3,8)$ & 26.6 & 27 & 73.03 & 0.1964 & 0.76 \\
$\mathrm{r}(3,8 \mathrm{~A})$ & 7 & 11.5 & 88.85 & 0.5092 & 0.95 \\
$\mathrm{r}(4,8)$ & 20.8 & 16.7 & 82.98 & 0.3428 & 0.84 \\
$\mathrm{r}(4,8 \mathrm{~A})$ & 4 & 7.8 & 92.49 & 0.6252 & 0.97 \\
$\mathrm{~d}(2,8)$ & 23.3 & 22.7 & 77.25 & 0.2521 & 0.83 \\
$\mathrm{~d}(4,8)$ & 23.5 & 18.5 & 81.12 & 0.3037 & 0.82 \\
$\mathrm{~d}(4,8 \mathrm{~A})$ & 5 & 11.3 & 89.18 & 0.5236 & 0.96 \\
$\mathrm{n}(2,8)$ & 23.8 & 11.8 & 87.28 & 0.4182 & 0.86 \\
$\mathrm{n}(2,8 \mathrm{~A})$ & 3.3 & 6.7 & 93.56 & 0.6650 & 0.98 \\
$\mathrm{n}(3,8)$ & 27.1 & 25.8 & 74.10 & 0.2052 & 0.76 \\
$\mathrm{n}(3,8 \mathrm{~A})$ & 6.3 & 12.8 & 87.70 & 0.4829 & 0.95 \\
$\mathrm{n}(4,8)$ & 19.6 & 19.2 & 80.77 & 0.3113 & 0.84 \\
$\mathrm{n}(4,8 \mathrm{~A})$ & 5 & 6 & 94.08 & 0.6809 & 0.98 \\
\hline
\end{tabular}

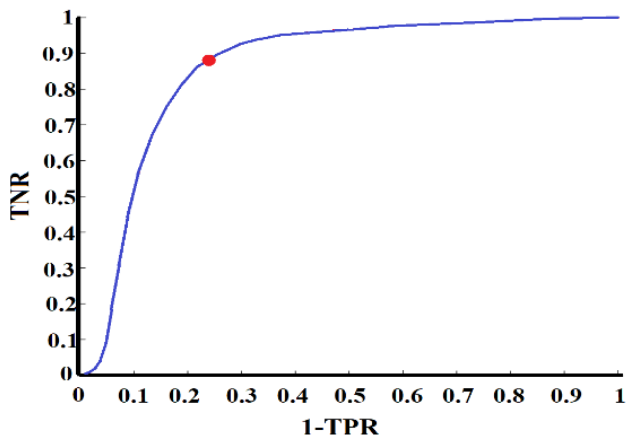

(a)

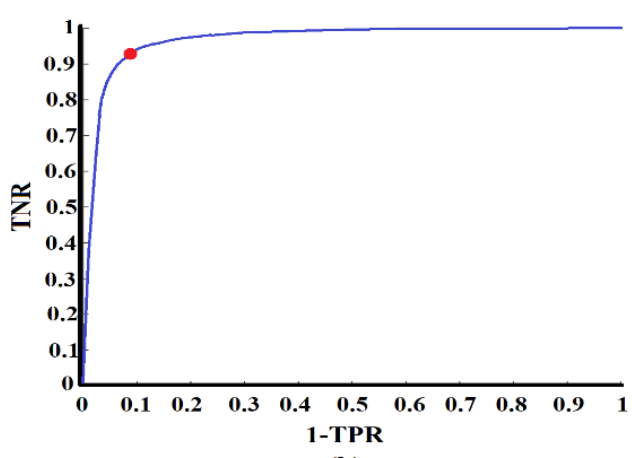

(b)

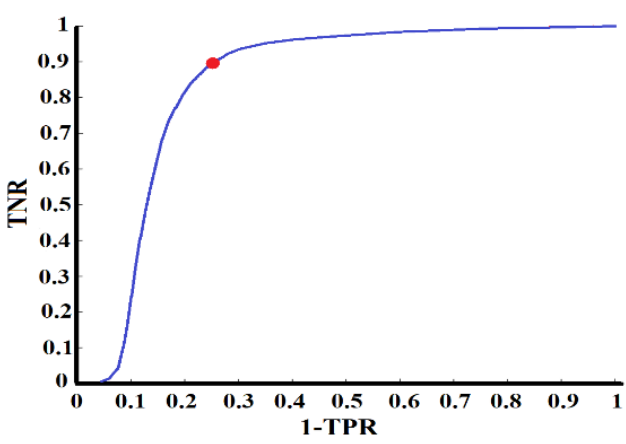

(c)

Figure 7. ROC curves for spectral feature $\mathrm{R}(2) / \mathrm{R}(8)(\mathrm{a})$, $R(4)-R(8 A)$ (b) and [R(4)-R(8A)]/[R(4)+R(8A)] (c). The red dot shows the index's ideal threshold. 
Indices can be classified into two categories: visible-NIR and visible-narrow NIR band combinations. According to the calculated statistical parameters, the superiority of the visiblenarrow NIR combinations is evident. Table 4, shows the comparison of these two index categories.

Table 4. Comparison of visible-narrow NIR and visible-NIR band combinations in HAB detecting

\begin{tabular}{ccc}
\hline $\begin{array}{c}\text { Statistical } \\
\text { parameter }\end{array}$ & $\begin{array}{c}\text { Visible-NIR band } \\
\text { combinations }\end{array}$ & $\begin{array}{c}\text { Visible- } \\
\text { narrowNIR band } \\
\text { combinations }\end{array}$ \\
\hline Type I error (\%) & 21.72 & 6.21 \\
Type II error (\%) & 20.02 & 8.94 \\
Accuracy (\%) & 79.74 & 91.39 \\
Kappa & 0.2941 & 0.5945 \\
AUC & 82.12 & 0.96 \\
\hline
\end{tabular}

Therefore, some spectral indices which can be generated using Sentinel-2 satellite images (especially visible-narrow NIR band combinations) have the ability to detect HABs. Using sentinel-2 high spatial and temporal resolution satellite images, the right indices and their corresponding threshold, we can detect and monitor HABs more accurate in small areas.

\section{REFERENCES}

Ahn, Y.H., Shanmugam, P., 2006. Detecting the red tide algal blooms from satellite ocean color observations in optically complex Northeast-Asia coastal waters. Remote Sensing of Environment 103, 419-437

Ahn, Y.-H. et al., 2006. Satellite detection of harmful algal bloom occurrences in Korean waters. Harmful Algae 5, 213-231

Anderson, C.R. et al., 2011. Detecting toxic diatom blooms from ocean color and a regional ocean model. Geophysical Research Letters 38 (4), L04603

Banks, A.C. et al., 2012. A satellite ocean color observation operator system for eutrophication assessment in coastal waters. Journal of Marine Systems 94 (Suppl.), S2-S15

Blondeau-Patissier, D. et al., 2014. A review of ocean color remote sensing methods and statistical techniques for the detection, mapping and analysis of phytoplankton blooms in coastal and open oceans. Progress in Oceanography, 123, 123144

Carvalho, G.A. et al., 2011. Long-term evaluation of three satellite ocean color algorithms for identifying harmful algal blooms (Karenia brevis) along the west coast of Florida: a matchup assessment. Remote Sensing of Environment 115, 1-18

Gitelson, A.A. et al., 2009. A bio-optical algorithm for the remote estimation of the chlorophyll-a concentration in case 2 waters. Environmental Research Letters 4, 5

Kahru, M. et al., 2004. MODIS detects a devastating algal bloom in paracas bay, Peru. Eos, Transactions, American Geophysical Union 85, 465-472

Kurekin, A.A., Miller, P.I., Van der Woerd, H.J., 2014. Satellite discrimination of Karenia mikimotoi and Phaeocystis harmful algal blooms in European coastal waters: merged classification of ocean colour data. Harmful Algae 31, 163-176
Matthews, M.W. et al., 2012. An algorithm for detecting trophic status (chlorophylla), cyanobacterial-dominance, surface scums and floating vegetation in Inland and coastal waters. Remote Sensing of Environment 124, 637-652

Miller, P.I. et al., 2006. SeaWiFS discrimination of harmful algal bloom evolution. International Journal of Remote Sensing 27 , 2287-2301

Richardson, K., 1997. Harmful or exceptional phytoplankton blooms in the marine ecosystem. Advances in Marine Biology $31,301-385$

Shanmugam, P. et al., 2008. SeaWiFS sensing of hazardous algal blooms and their underlying mechanisms in shelf-slope waters of the Northwest Pacific during summer. Remote Sensing of Environment 112, 3248-3270

Shutler, J.D. et al., 2012. An adaptive approach to detect highbiomass algal blooms from EO chlorophyll-a data in support of harmful algal bloom monitoring. Remote Sensing Letters 3, 101110

Siswanto, E. et al., 2013. Detection of harmful algal blooms of Karenia Mikimotoi using MODIS measurements: a case study of Seto-Inland Sea, Japan. Remote Sensing of Environment 129, 185-196

Tang, D. et al., 2006. Satellite evidence of harmful algal blooms and related oceanographic features in the Bohai Sea during Autumn 1998. Advances in Space Research 37, 681-689

Yunus, A. et al., 2015. Remote sensing of chlorophyll-aas a measure of red tide in Tokyo Bay using hotspot analysis. Remote Sensing Applications: Society and Environment, 2, 11-25

Zhao, D. et al., 2010. The relation of chlorophyll-a concentration with the reflectance peak near $700 \mathrm{~nm}$ in algae-dominated waters and sensitivity of fluorescence algorithms for detecting algal bloom. International Journal of Remote Sensing 31 (10) 